\title{
Evaluation Factors Influencing the Use of Go-Pay with the Unified Theory of Acceptance and Use of Technology 2 Model
}

\author{
Bismo Batoro* \\ School of Business and Management \\ Institut Teknologi Bandung \\ Bandung, Indonesia \\ *bismo.batoro@sbm-itb.ac.id
}

\begin{abstract}
The purpose of this study is to evaluate and collect information by identifying factors that can influence Behavioral Intention and Use Behavior for the community to use Go-Pay as a payment instrument. This study described the condition of the use of Go-Pay by Generation $Z$ based on the variables contained in the UTAUT 2 research model. The UTAUT 2 model was formed on seven independent variables, namely Performance Expectancy, Effort Expectancy, Social Influence, Facilitating Conditions, Hedonism Motivation, Price Value, and Habit. These variables are tested to construct the dependent variable, namely Behavioral Intention, and Use behavior. The results of the test identified that Performance Expectancy, Effort Expectancy, Hedonism Motivation, and Habit influenced Behavioral intention. While behavioral intention and habits influence user behavior. Other findings from this study state that of all variables, habit is a variable that has the most significant impact that affects both behavioral intention and use behavior.
\end{abstract}

Keywords: evaluate, payment instrument, Go-Pay, generation Z, UTAUT 2

\section{INTRODUCTION}

The development of information technology is currently increasing very rapidly. Over time, the development of information technology continues to issue innovations - one of the technology industries that has experienced rapid development in financial technology (Fintech). According to the OJK (Otoritas Jasa Keuangan) Report in 2019, the number of Financial Technology companies licensed and registered by OJK increased from December 2017 to February 2019 by $441 \%$. Payment sector seems the most trending sector of Fintech industry. Based on data obtained from the report of OJK, payment is a sector that dominates the financial technology industry with a percentage of $43 \%$, followed by loans with a percentage of $17 \%$, and the rest are crowdfunding and financial planning. Some brands of electronic money products that have high popularity in Indonesia are Go-Pay, OVO, and LinkAja. Prior to a survey conducted by Dailysocial in 2018, Go-Pay is the most popular electronic money in the market. Although Go-Pay has held the position of the most popular electronic money, Go-Pay still needs to maintain its performance to maintain its customers as demand growth is inclining. Liu, Maggie, \& Lee, through his research, showed that the increase in retaining customers resulted in more significant benefits for the company [1]. As the market demand was always increasing annually, Go-Jek must be able to read the trend in the future. According to Puspaningtyas, the company must be able to identify the market behavior and the dynamic of the market trend to be able to fulfil the demand and continuously increase the service quality [2].

This research evaluated Go-Pay usage activities. According to Stufflebeam, the definition of evaluation is the process of capture, searching, and providing information that is useful for decision-makers to determine alternative decisions [3]. Stufflebeam explains that evaluation should help the development, implementation, needs of a program, improvement of programs, and accountability of stakeholders [3]. So, by evaluating, Go-Jek can develop, implement, and improve programs so that it can improve Go-Pay's services as a payment instrument

In this case, there is a research model for measuring and evaluating the use of technology. The research model used in this research is UTAUT 2 (Unified Theory of Acceptance and Use of Technology 2). The UTAUT 2 model aims to identify seven essential variables from technology acceptance and use [4]. The seven variables are Performance Expectancy (PE), Effort Expectancy (EE), Social Influence (SI), Facilitating Condition (FC), Hedonic Motivation (HM), Price Value (PV), and Habit (HA)

This research used an approach that targeted Generation $\mathrm{Z}$ in the city of Bandung. Linnes and Metcalf state that Generation $\mathrm{Z}$ is the most dependent generation in information technology [4]. In addition, Generation $\mathrm{Z}$ is also the generation that has the highest level of acceptance of technology, among other generations [5]. Not to mention, according to BPS Bandung City in 2016, Generation $\mathrm{Z}$ held the densest number of populations among other generations. This research focused on research in Bandung due to consideration that Bandung is one of the cities in Indonesia that can adapt to technological developments quickly [6]. 
From the background described, the researcher wants to evaluate the use of Go-Pay on Generation $\mathrm{Z}$ in the city of Bandung. Thus, the title of the research that the researchers propose is "Evaluation Factor Influencing the Use of Go-Pay with the Unified Theory of Acceptance and Use of Technology 2 Model."

\section{A. Research Objective}

The research objective is to examine the relationship between the variables from Extended UTAUT2 model consists of Performance Expectancy (PE), Effort Expectancy (EE), Social Influence (SI), Facilitating Condition (FC), Hedonic Motivation (HM), Price Value (PV), and Habit (HA) towards the Behavioral Intention and Actual Use.

From the description, the hypothesis formulated in this study are:

H1: Performance Expectancy (PE) positively influences Behaviour Intention (BI) to use Go-Pay as a payment instrument.

H2: Effort Expectancy (EE) positively influences Behavioral Intention (BI) to use Go-Pay as a payment instrument.

H3: Social Influence (SI) positively influences Behavioral Intention (BI) to use Go-Pay as a payment instrument.

H4: Facilitating Condition (FC) positively influences Behavioral Intention (BI) to use Go-Pay as a payment instrument.

H5: Hedonic Motivation (HM) positively influences Behavioral Intention (BI) to use Go-Pay as a payment instrument

H6: Price Value (PV) Positive influence of Behavioral Intentional (BI) to use Go-Pay as a payment instrument.

H7: Habit (HA) positively influences Behavioral Intention (BI) to use Go-Pay as a payment instrument.

H8: Facilitating Condition (FC) positively influences Use Behavior (UB) to use Go-Pay as a payment instrument.

H9: Habit (HA) positively influences Use Behavior (UB) to use Go-Pay as a payment instrument.

H10: Behavioral Intention (BI) positively influences Use Behavior (UB) to use Go-Pay as a payment instrument.

\section{B. Scope and Limitation}

This research covers the evaluation of the use of Go-Pay as a payment instrument both online and offline payment by GoJek application users aged 9 to 24 and domiciled in the city of Bandung.

\section{METHODS}

\section{A. Sample and Population}

The population in this research were Go-Pay users in Bandung city aged 9 to 24 years. Based on data obtained from the Badan Pusat Statistik (BPS) of Bandung City in 2016, the population of the city of Bandung, aged 9 to 24 years in 2016 amounted to 847845 people. The sampling technique is purposive sampling. Purposive sampling is done to select samples from the population, where the criteria chosen are according to the requirements of the researcher. The following are the criteria for the profile of respondents in this study: Age ranges from 9 to 24 years, must-have used Go-Pay, and domiciled in the city of Bandung

In PLS-SEM, the determination of the sample for research is set at ten times the number of paths that lead to latent variables [7]. Due to the number of lines in this study amounting to 10 paths, the minimum number of samples of this study is 100 people.

\section{B. Data Collection Method}

The method to collect the data is by conducting survey. The survey is conducted by the researcher to get the data by using a research instrument in the form of a questionnaire. The process of distributing questionnaires is done indirectly. Indirect distribution was carried out by researchers through social media such as WhatsApp and Instagram with the feature of filling in the google form online questionnaire to fill it out. This questionnaire is distributed and filled out validly but sorted according to the profile of the respondent who meets the research criteria. The questionnaire was distributed from May 25, 2019, to June 1, 2019.

\section{Data Analysis Method}

Data analysis method used in this research was Partial Least Square-Structural Equation Model (PLS-SEM). PLSSEM method was conducted to identify relationship among the independent variables towards the dependent variables [8].

In PLS-SEM, validity and reliability of all item questionnaires which construct the variable in the framework is tested to evaluate the measurement model. The result of the evaluation determined and ensure that the data can be appropriately used for further analysis [8].

\section{RESULTS AND DISCUSSION}

\section{A. Validity and Reliability Test}

Reliability testing stage was done by reviewing the composite reliability (CR) value with a threshold above 0.7 . If the Composite Reliability value is above 0.7 , therefore the indicator stated as reliable.

TABLE I. RELIABILITY TEST RESUlT

\begin{tabular}{|l|c|}
\hline \multicolumn{1}{|c|}{ Indicator } & Composite Reliability \\
\hline Use Behavior & 0.922 \\
\hline Behavioral Intention & 0.916 \\
\hline Effort Expectancy & 0.895 \\
\hline Facilitating Condition & 0.862 \\
\hline Habit & 0.952 \\
\hline Hedonic Motivation & 0.867 \\
\hline Performance Expectancy & 0.866 \\
\hline Price Value & 0.908 \\
\hline Social Influence & 0.862 \\
\hline
\end{tabular}


towards Use Behavior with the value of T-test 0.613, Price Value towards Behavioural Intention with T-value test 1.41, and Social Influence towards Behavioral Intention with a T-test value of 1,323 . Thus, this result shows that out of 10 hypotheses, there are 4 hypotheses that are not accepted

2) Path Coefficient: Path coefficient testing was done by determining how much influence an independent variable has on the dependent variable. The following are the data from the path coefficient test.

TABLE IV. PATH CoefFicient TeSt Result

TABLE II. VALIDITY TEST RESULT

\begin{tabular}{|c|c|}
\hline Indicator & Average Variance Extracted (AVE) \\
\hline UB & 0.855 \\
\hline BI & 0.731 \\
\hline EE & 0.68 \\
\hline FC & 0.675 \\
\hline HA & 0.868 \\
\hline HM & 0.686 \\
\hline PE & 0.617 \\
\hline PV & 0.714 \\
\hline SI & 0.675 \\
\hline
\end{tabular}

As all of the AVE's value of indicators are above 0.5, then all of the item questionnaires were determined as valid.

Based on the two stages of testing that have been carried out in the analysis of the previous router model, it can be concluded that the model proposed in this study has good characteristics statistically, according to the requirements of each stage in the measurement model. So that conclusions can be drawn from the results of model measurement analysis that the model meets the requirements and is feasible to proceed to the inner model testing stage.

\section{B. Hypothesis Testing Result}

1) T-Test: At the testing stage, this T-test was carried out through the bootstrapping method on the SmartPLS, using a two-tailed test with a significance level of $5 \%$ to test the research hypotheses. The hypothesis are accepted if it has a TValue greater than 1.984. The following are the results of the T-test.

TABLE III. T-TEST RESULT

\begin{tabular}{|l|l|l|l|}
\hline Indicator & T-Statistics & P Values & Information \\
\hline $\mathrm{BI} \rightarrow \mathrm{UB}$ & 7.858 & 0 & Significant \\
\hline $\mathrm{EE} \rightarrow \mathrm{BI}$ & 2.535 & 0.012 & Significant \\
\hline $\mathrm{FC} \rightarrow \mathrm{BI}$ & 0.885 & 0.377 & Not Significant \\
\hline $\mathrm{FC} \rightarrow \mathrm{UB}$ & 0.613 & 0.54 & Not Significant \\
\hline $\mathrm{HA} \rightarrow \mathrm{BI}$ & 4.877 & 0 & Significant \\
\hline $\mathrm{HA} \rightarrow \mathrm{UB}$ & 8.626 & 0 & Significant \\
\hline $\mathrm{HM} \rightarrow \mathrm{BI}$ & 2.295 & 0.022 & Significant \\
\hline $\mathrm{PE} \rightarrow \mathrm{BI}$ & 2.075 & 0.039 & Significant \\
\hline $\mathrm{PV} \rightarrow \mathrm{BI}$ & 1.41 & 0.159 & Not Significant \\
\hline $\mathrm{SI} \rightarrow \mathrm{BI}$ & 1.323 & 0.187 & Not Significant \\
\hline
\end{tabular}

The results of the T-test test in the table informs that there is a T-test value of less than 1.984, namely the relationship between Facilitating Condition towards Behavioral Intention variables with the value of T-test 0.885 , Facilitating Condition

\begin{tabular}{|c|c|}
\hline Indicator & Path Coefficient ( $\beta$ ) \\
\hline $\mathrm{HA} \rightarrow \mathrm{BI}$ & 0.274 \\
\hline $\mathrm{EE} \rightarrow \mathrm{BI}$ & 0.17 \\
\hline $\mathrm{HM} \rightarrow \mathrm{BI}$ & 0.17 \\
\hline $\mathrm{PE} \rightarrow \mathrm{BI}$ & 0.138 \\
\hline $\mathrm{PV} \rightarrow \mathrm{BI}$ & 0.088 \\
\hline $\mathrm{SI} \rightarrow \mathrm{BI}$ & 0.083 \\
\hline $\mathrm{FC} \rightarrow \mathrm{BI}$ & 0.049 \\
\hline $\mathrm{HA} \rightarrow \mathrm{UB}$ & 0.457 \\
\hline $\mathrm{BI} \rightarrow \mathrm{UB}$ & 0.448 \\
\hline $\mathrm{FC} \rightarrow \mathrm{UB}$ & -0.023 \\
\hline
\end{tabular}

The table shows that all indicator has the path coefficients more than zero, except indicator Facilitating Condition towards Use Behavior. If the path coefficient value is more than zero, then the relationship among the independent towards the dependent variables are positively significant. Vice versa, if the path coefficient value less than zero meaning that the relationship is negative.

\section{CONCLUSIONS}

Based on the results of the analysis and discussion that the researcher has conducted, some conclusions that the researcher can provide are as follows:

- Habit towards Behavioral Intention, Habit towards Use Behavior, Behavioral Intention towards Use Behavior are statistically accepted because it has at-value of more than 1,984 (significant). Which means that the results of the hypothesis can represent the population of the research subject in this study, namely Generation $Z$ GoPay users in the city of Bandung. Other hypotheses, namely Social Influence towards Behavioral Intention, Facilitating Condition towards Behavioral Intention, Price Value towards Behavioral Intention, Facilitating Condition towards Use Behavior are not accepted because they have a statistically t-value of less than 1.984 (not significant). Which means that the hypothesis cannot represent the population of the research subject, but can only represent the results of the respondents of this study.

- The habit has a large influence on the two dependent variables that influence it directly or indirectly, namely Behavioral Intention and Use Behavior. In the Habit towards Behavioral Intention path, the Habit variable has the greatest effect among the other independent variables. It statistically shows that the path Habit towards Behavioral Intention has the path coefficient 


\section{REFERENCES}

( $\beta)$ value of 0.274 , the highest among the other variables. Then in the Habit towards Use Behavior path, the Habit variable has the biggest influence among other variables because statistically. The habit has the path coefficient $(\beta)$ value of 0.457 , the highest among the other variables.

- This research took sample from Generation $\mathrm{Z}$ in Bandung City because Generation $\mathrm{Z}$ has the highest technology acceptance and has the largest percentage of proportion in Bandung City among the other generations. Also, this research proposed modified new framework which only use Habit, Performance Expectancy, Behavioral Intention, Effort Expectancy as the dependent variables. This framework only suitable with similar population of respondent taken.
[1] M.W. Liu, L. Zhang and H.T. Keh, "Consumer Responses to High Service Attentiveness: A Cross-Cultural Examination," Journal of International Marketing, vol. 4, 2019.

[2] M. Puspaningtyas, "Analisis Pemasaran Jasa," Jurnal Dinamika Dotcom, vol. 2, no. 1, 2011.

[3] D.A. Stufflebeam, "Tribute to Egon Guba," American Evaluation Association, pp. 325-327, 2008.

[4] V. Venkatesh, J.Y. Thong and X. Xu, "Consumer Acceptance And Use Of Information Technology: Extending The Unified Theory Of Acceptance And Use Of Technology," MIS Quarterly, pp. 157-178, 2012.

[5] C. Linnes and B. Metcalf, "iGeneration And Their Acceptance of Technology," International Journal of Management \& Information System, vol. 2, 2017.

[6] T. Widodo and P.V. Shara, "Penerapan Model Unified Theory Of Acceptance And Use Of Technology (UTAUT) Untuk Menganalisis Minat Pengguna Smartphone Di Kota Bandung," ResearchGate, 2018.

[7] J.F. Hair, M. Sarstedt, L. Hopkins and V.G. Kuppelwieser, "Partial Least Squares Structural Equation Modeling (PLS-SEM)," European Business Review, pp. 106-121, 2014.

[8] J.F. Hair, W.C. Black, B.J. Babin and R.E. Anderson, Multivariate Data Analysis. Pearson Education Limited, 2014. 